\title{
Propagation of ELF Radiation from RS-LC System and Red Sprites in Earth- Ionosphere Waveguide
}

\author{
Manoj Kumar Paras ${ }^{1}$, Jagdish Rai ${ }^{1,2}$ \\ ${ }^{1}$ Department of Physics, Indian Institute of Technology Roorkee, Roorkee-247667, Uttarakhand, India \\ ${ }^{2}$ Department of Physics and Astronomy, Clemson University, Clemson, SC 29631, U.S.A \\ *mkparas.iitr@gmail.com
}

\begin{abstract}
In this paper, two different mechanisms return stroke-lateral corona (RS-LC) system and red sprites which excite Earthionosphere waveguide have been discussed. The electric and magnetic fields from RS-LC system and red sprites in the Earth-ionosphere waveguide have been calculated. It has been found that red sprites contribute to the Schumann resonances (SR) greatly as compared to the RS-LC system.
\end{abstract}

\section{Introduction}

Lightning discharge is primarily considered as the source of radio frequencies ranging from a few Hertz to microwaves. Return stroke is the most intense form of cloud-to-ground lightning. The maximum radiated power from lightning lies in the extremely low frequency (ELF) to very low frequency (VLF) region. Earth and ionosphere having good electrical conductivities at ELF and VLF form a natural cavity which is commonly known as Earth-ionosphere waveguide [1]. UHF generated from lightning discharge can penetrate the ionosphere but the ELF and VLF waves are reflected from the ionospheric boundary and propagate within the Earthionosphere waveguide. The Earth-ionosphere waveguide behaves like a resonator at ELF frequencies and amplifies the signals from lightning at the resonance frequencies. Schumann (1952) first studied theoretically about the global resonance of the Earth-ionosphere waveguide system known today as the Schumann resonances (SR). The resonant frequency of $n^{\text {th }}$ mode $f_{n}$ for an ideal Earth-ionosphere waveguide is given by [2]

$$
f_{n}=\frac{c}{2 \pi R_{e}} \sqrt{n(n+1)}
$$

where, $\mathrm{n}$ is an integer; $\mathrm{c}$ is the velocity of light; and $\mathrm{R}_{\mathrm{e}}$ is the Earth's radius.

According to equation (1), the first five resonance frequencies are $10.6,18.4,26.0,35.5$, and $41.1 \mathrm{~Hz}$. In the above calculation (equation 1), the ionosphere is considered as the perfect conductor, but in reality it has some finite conductivity. The SR frequencies " $\omega$ " can be calculated using the ionospheric parameters by following relation [3]

$$
\omega=\frac{c \sqrt{n(n+1)}}{R_{e}} \cdot \frac{1}{\sqrt{1-\frac{2 h_{s}}{a}\left[\gamma+\ln \left(\frac{\omega_{02} h_{s}}{c} \sqrt{\frac{i \omega}{v_{e 2}}}\right)\right]}}
$$

$\mathrm{n}=1,2,3, \ldots \ldots$, where, $\gamma=0.577$ is Euler's constant; " $\mathrm{a}$ " is height of the base of ionospheric D region; " $h_{\mathrm{s}}$ " is the scale height; $\omega_{02}=N_{2} e^{2} / m_{e} \varepsilon_{0}$ is the plasma frequency $\left(\mathrm{N}_{2}\right.$ is the electron density at "a"), $m_{e}$ and e are the mass and charge of electron respectively, $\varepsilon_{0}$ is the permittivity of free space and $v_{\mathrm{e} 2}$ is the electron collision frequency at "a".

They [3] calculated first three SR frequencies to be $\mathrm{f}_{1}=(7.71+0.43 \mathrm{i}), \mathrm{f}_{2}=(13.62+0.78 \mathrm{i})$ and $\mathrm{f}_{3}=(19.51+1.15 \mathrm{i}) \mathrm{Hz}$ using ionospheric parameters a $=55 \mathrm{~km}, \mathrm{~h}_{\mathrm{s}}=7 \mathrm{~km}, \mathrm{~N}_{2}=4 \times 10^{7}$ $\mathrm{m}^{-3}, \mathrm{v}_{\mathrm{e} 2}=10^{7} \mathrm{~s}^{-1}$. Madden and Thompson [4] obtained the SR frequencies to be $7.8,14.1,20.3,26.3$ and $32.5 \mathrm{~Hz}$. The shifting of the SR to lower frequencies from its ideal values (equation 1) is because of energy loss due to the finite ionospheric conductivity. The maximum power in the ELF and VLF range is radiated from return strokes. Paras and Rai $[5,6]$ found that the red sprites are also the source of strong ELF radiation. However, we do not know as which one contributes to the Schumann resonances. The purpose of the present paper is to have a comparative study of electromagnetic wave propagation from RS-LC system and red sprites in the Earth-ionosphere waveguide contributing to Schumann resonances.

\section{Theory}

ELF radiation having frequency $3-60 \mathrm{~Hz}$ can propagate within the Earth-ionosphere waveguide without significant attenuation. Using the spherical polar coordinates $(r, \theta, \phi)$ with the Earth's center as the origin, the electric and magnetic fields associated with these ELF in Earthionosphere waveguide are given by [7]

$$
\begin{aligned}
& E_{r}(\omega)=-\frac{M_{c}(\omega) i v(v+1)}{4 \pi \varepsilon_{0} h R_{e}^{2} \omega} \sum_{n=0}^{\infty} \frac{(2 n+1) P_{n}(\cos \theta)}{n(n+1)-v(v+1)} \\
& H_{\phi}(\omega)=\frac{M_{c}(\omega)}{4 \pi h R_{e}} \sum_{n=1}^{\infty} \frac{(2 n+1) P_{n}^{1}(\cos \theta)}{n(n+1)-v(v+1)}
\end{aligned}
$$

where, $M_{c}(\omega)$ is the current moment of the source in frequency domain; $\mathrm{R}_{\mathrm{e}}=6400 \mathrm{~km}$ is the Earth's radius; $\mathrm{h}=90$ $\mathrm{km}$ is the ionosphere height; the field source is positioned on the ground surface at the pole $(\theta=0)$, so that $\theta$ is the angular source-observer distance; $\omega=2 \pi \mathrm{f}$ is the angular frequency; $\varepsilon_{0}$ is the permittivity of free space; $P_{n}(\cos \theta)$ and $P_{n}^{1}(\cos \theta)$ are the Legendre and associated Legendre polynomials of the 
order $\mathrm{n}$; and $\mathrm{v}(\mathrm{f})$ is the propagation parameter of ELF radio waves.

The parameter " $v(f)$ " is given by [7]

$$
v(f)=\sqrt{\frac{1}{4}+\left(k R_{e}\right)^{2} S_{v}^{2}}-\frac{1}{2}
$$

where,

$$
\begin{aligned}
& S_{v}=\frac{c}{V}-i(5.49) \frac{\chi}{f} \\
& \frac{c}{V}=1.64-0.1759 \log f+0.01791(\log f)^{2}
\end{aligned}
$$

"c" and "V" are the velocity of light and phase velocity of wave in Earth-ionosphere waveguide respectively; and the wave attenuation factor " $\chi$ " is given by

$$
\chi=0.063 f^{0.64}
$$

The schematic diagram of calculation model and coordinate system has been shown in Fig. 1.

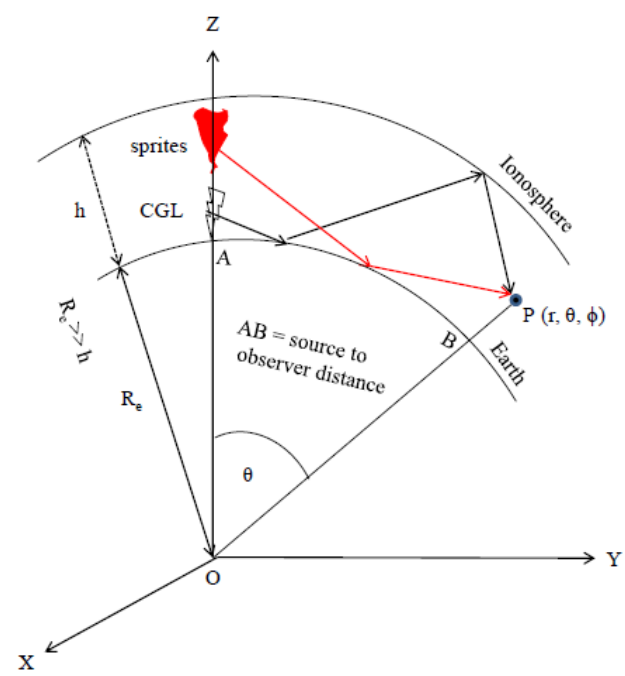

Figure 1: Schematic diagram of calculation model and coordinate system. The ELF radiation from red sprites and cloud-to-ground lightning (CGL) travel in the Earthionosphere waveguide and observed at point $\mathrm{P}(\mathrm{r}, \theta, \phi)$. Here, the observation point is on the surface of earth i.e. $r=R_{e}$.

\section{Return Stroke-Lateral Corona System}

Cloud-to-ground lightning contains two different types of current. The first one and most intense is the return stroke current. It can ranges from 10-100 kA with duration of $100-$ $200 \mu$ s [8]. Typical length of return stroke ranges from 5-10 $\mathrm{km}$. Return stroke is the response of stepped leader which is formed at the base of the thundercloud and carry charge towards the ground. The propagation of stepped leaders and return strokes has been successfully described by considering the potential gradient waves $[9,10]$. The velocity and current expressions for return strokes are given by $[5,10]$

$$
V_{r s}(t)=V_{0}\left(e^{-a t}-e^{-b t}\right)
$$

$$
I_{r S}(t)=I_{0}\left(e^{-\alpha t}-e^{-\beta t}\right)
$$

where, $\mathrm{V}_{0}=9 \times 10^{7} \mathrm{~m} / \mathrm{s} ; \mathrm{a}=3 \times 10^{4} \mathrm{~s}^{-1} ; \mathrm{b}=7 \times 10^{5} \mathrm{~s}^{-1} ; \mathrm{I}_{0}=22 \mathrm{kA}$; $\alpha=1.6 \times 10^{4} \mathrm{~s}^{-1} ; \beta=5 \times 10^{5} \mathrm{~s}^{-1}$.

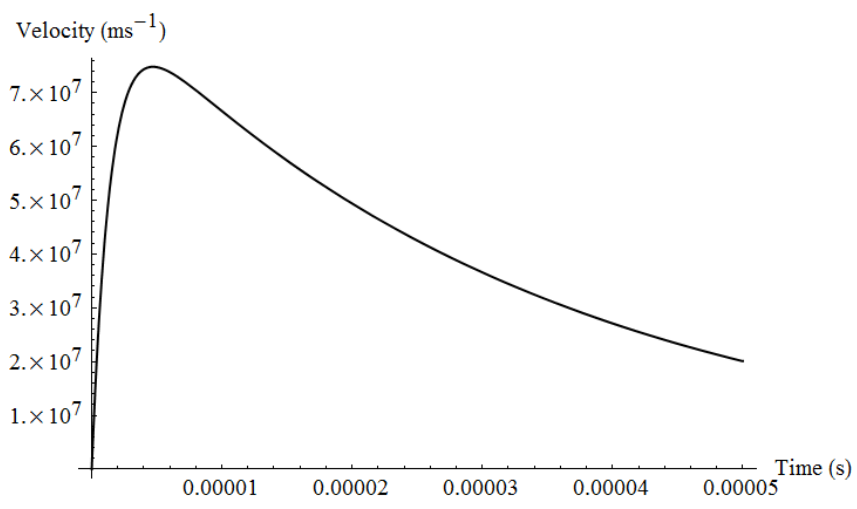

Figure 2: Velocity of RS-LC system with time.

Below the tip of the return stroke, the whole channel up to ground surface is at high potential than the surrounding medium left by stepped leader. The negative ions and electrons along the entire channel from tip to the ground move towards the highly conducting return stroke core and constitute a current which immediately flows to the ground through this channel. Since this current is developed due to the radial movement of negative ions and electrons, it is known as "lateral corona current". The mathematical expression is given by [11]

$$
\begin{aligned}
I_{l c}(t) & =\frac{K V^{2} V_{0}}{a b}\left[(b-a) \exp \left(\frac{-2 t}{C R}\right)\right. \\
& \left.-b \exp \left[-\left(a+\frac{2}{C R}\right) t\right]+a \exp \left[-\left(b+\frac{2}{C R}\right) t\right]\right]
\end{aligned}
$$

where, $\mathrm{K}=$ Corona constant $\left(10^{-16} \mathrm{AV}^{-2} \mathrm{~m}^{-1} \mathrm{~s}^{-1}\right)$; $\mathrm{V}=$ Potential difference between the return stroke and the leader sheath in volts and can be taken as $10^{8}$ Volts; $\mathrm{C}=$ Distributed capacity of the leader sheath-return stroke core in farads $/ \mathrm{m}$; $\mathrm{R}=$ Distributed resistance of the above configuration $\left(\mathrm{CR}=5.3865 \mathrm{~ms}\right.$ for $\left.\mathrm{I}_{0}=22 \mathrm{kA}\right)$.

Since both the currents flow simultaneously in the cloud-toground lightning channel and they are not separable. So, the total current is written by

$$
I_{\text {tot }}(t)=I_{r s}(t)+I_{l c}(t)
$$

The current moment $\mathrm{M}_{\mathrm{c}}$ associated with a current source is defined as the multiplication of the current in the channel of the source body and the distance travelled by it. The mathematical expression for $\mathrm{M}_{\mathrm{c}}$ is given by

$$
M_{c}(t)=2 I(t) \int_{0}^{t} V(t) d t
$$

where, $I(t)$ and $V(t)$ are the current and velocity of the system respectively. The velocity and current associated 
with RS-LC system have been shown in Fig. 2 and Fig. 3 respectively. Further, the current moment in time domain also has been shown in Fig. 4. The peak value of $M_{c}$ comes out to be around55 kA.km for the defined parameters of RSLC system.

Using the Fourier transformation technique, we calculated $\mathrm{M}_{\mathrm{c}}(\omega)$ the Fourier component of $\mathrm{M}_{\mathrm{c}}(\mathrm{t})$ for RS-LC system. Electric and magnetic fields associated with the ELF waves propagating within the Earth-ionosphere waveguide from RS-LC system have been calculated with the help of equations (3), (4) and (13). Fig. 5 and Fig. 6 show the electric field at distances of 1000 and $5000 \mathrm{~km}$ respectively from the current source. Similarly, magnetic field has been also calculated and shown in Fig. 7 and Fig. 8. The electric and magnetic fields due to RS-LC system come out to be of the order of $10^{-5} \mathrm{Vm}^{-1}$ and $10^{-8} \mathrm{Am}^{-1}$ respectively, and get peak at SR frequencies.

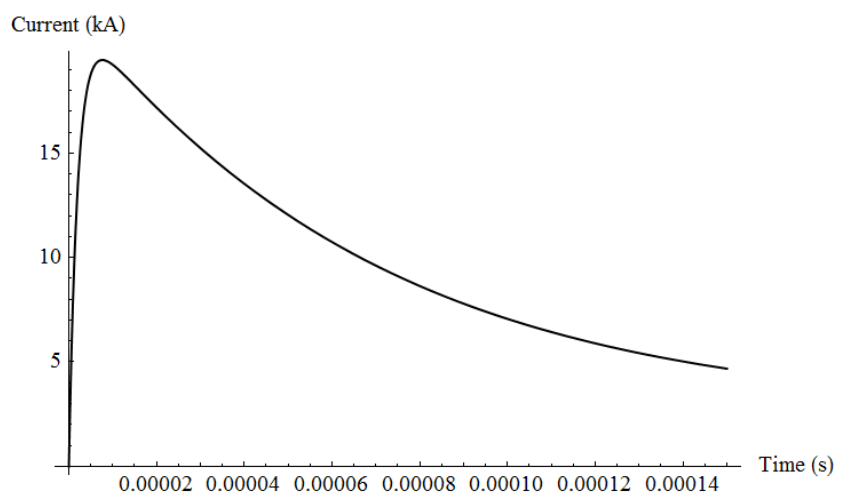

Figure 3: Current of RS-LC system with time.

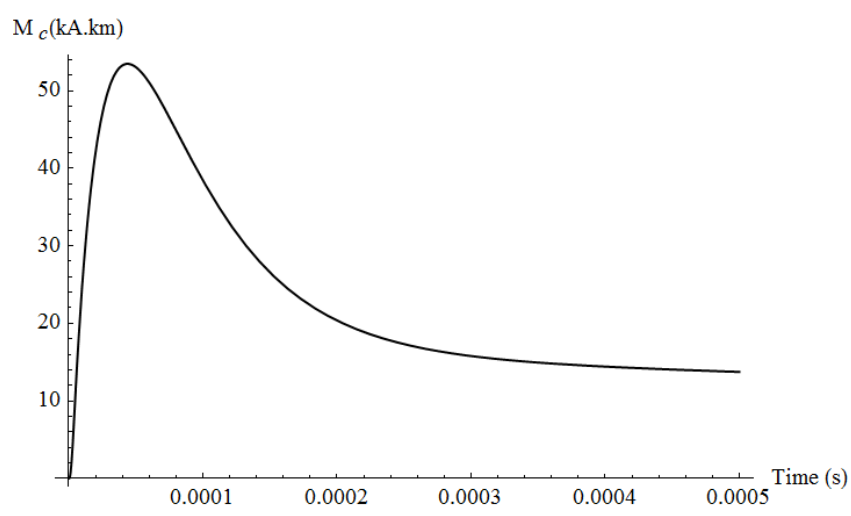

Figure 4: Current moment of RS-LC system with time.

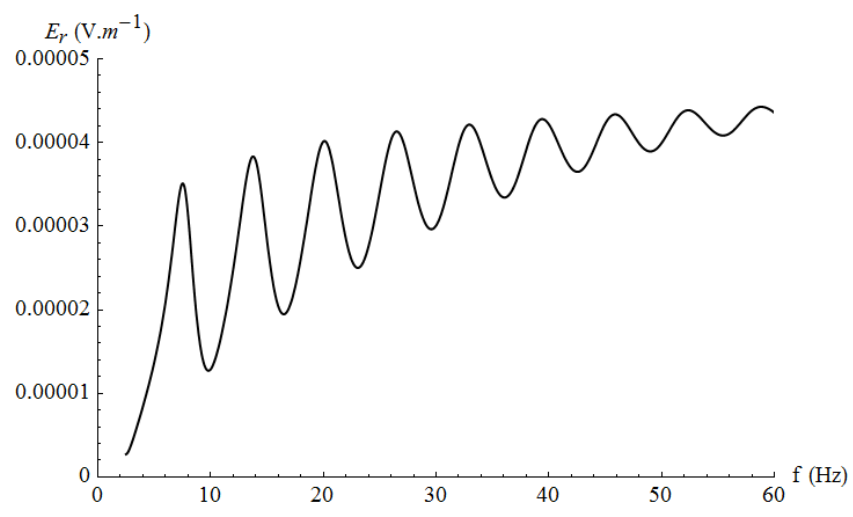

Figure 5: Electric field versus frequency at a distance of $1000 \mathrm{~km}$ from the source.

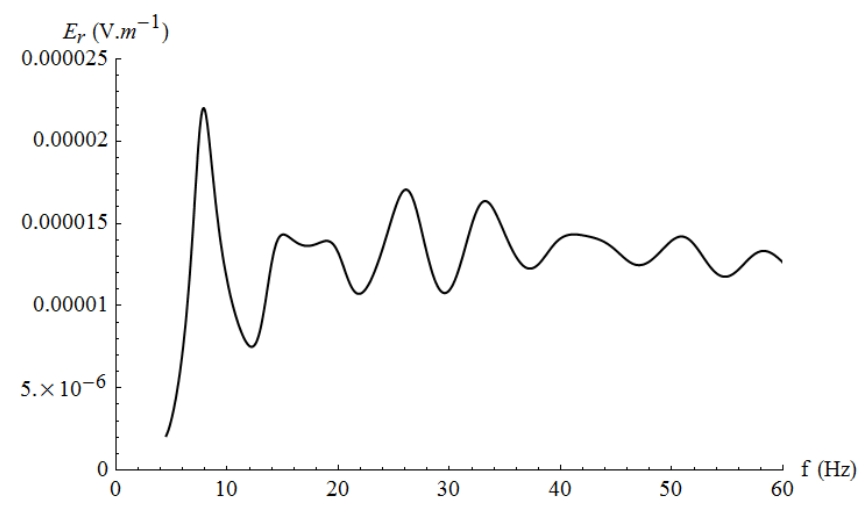

Figure 6: Electric field versus frequency at a distance of $5000 \mathrm{~km}$ from the source.

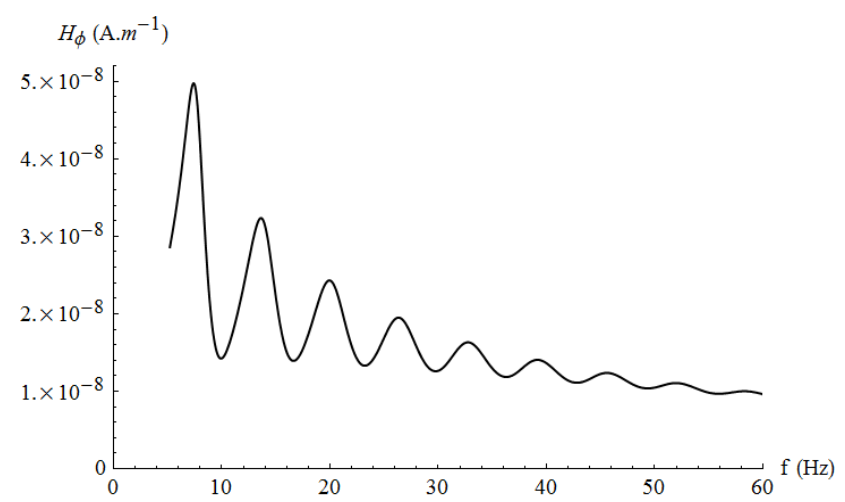

Figure 7: Magnetic field versus frequency at a distance of $1000 \mathrm{~km}$ from the source. 


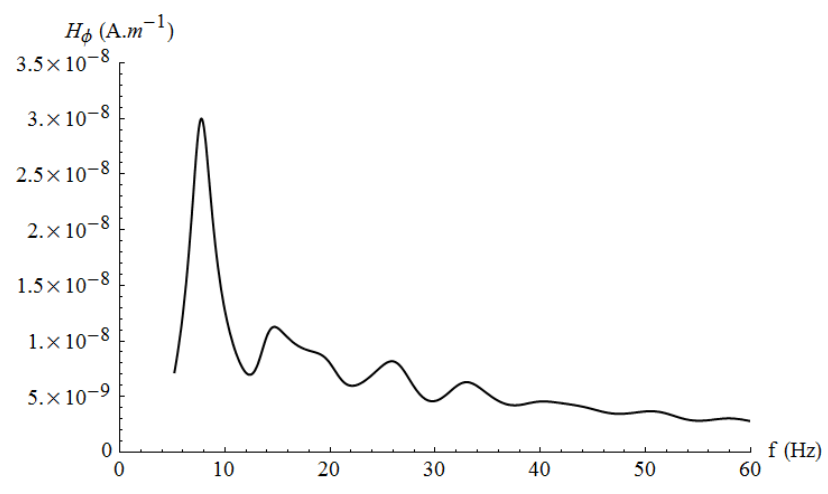

Figure 8: Magnetic field versus frequency at a distance of $5000 \mathrm{~km}$ from the source.

\section{Red Sprites}

Red sprites are the optical emissions in the upper atmosphere. Wilson (1925) first predicted about the ionization and breakdown of upper atmosphere. He recognized that the thundercloud electric field decreases with altitude $\mathrm{z}$ as $\sim \mathrm{Z}^{-3}$ and the critical breakdown electric field which decreases even much faster (proportional to the exponentially decreasing atmospheric density) leads to the result that there will be a height at which cloud electric field will exceeds the sparkling limit to produce upper atmospheric lightning discharges[12]. Latter, Franz et al. [13] reported the low-light-level TV images of these high altitude lightning discharges. Red sprites, blue jets and elves are some forms of high altitude lightning discharges which are categorized according to their shape, color and altitude of occurrence. Red sprites are the most frequent candidates among them. Sprites are luminous red structures that typically span the altitude ranges from $60-90 \mathrm{~km}$, often with faint bluish tendrils dangling below [14]. The lateral extent of sprites can ranges from $10-50 \mathrm{~km}$. Sprites are associated with the strong positive cloud-to-ground lightning and occur in the dying stage of the thunderstorm [15]. The mechanism for the generation of sprites is the "runaway breakdown" model, which describes that the large quasi-electrostatic fields developed in the upper atmosphere due to the strong positive cloud-to-ground lightning produce an upward traveling beam of $\sim 1 \mathrm{MeV}$ runaway electrons to produce optical emissions called red sprites. Sprites can propagate upwards or downwards from their point of origination. Downwards sprites can propagate with a maximum velocity of $3-10 \%$ of the speed of light [16]. The peak vertical current in the body of sprites can ranges from 1.6-3.3 kA [17]. Rycroft and Odzimek [18] have reported the values 5$10 \mathrm{kA}$.

The velocity and current expressions for red sprites are given by $[5,6]$

$$
\begin{aligned}
& V_{s p}(t)=V_{1} \exp \left[-\xi(t-\eta)^{2}\right] \\
& I_{s p}(t)=I_{1}\left(e^{-\gamma t}-e^{-\delta t}\right)
\end{aligned}
$$

where, $\mathrm{V}_{1}=1.16 \times 10^{7} \mathrm{~ms}^{-1} ; \xi=4.13 \times 10^{5} \mathrm{~s}^{-2} ; \eta=3.83 \times 10^{-3} \mathrm{~s}$; $\mathrm{I}_{1}=8.35 \times 10^{3} \mathrm{~A} ; \gamma=1.10 \times 10^{2} \mathrm{~s}^{-1}$; and $\delta=7.00 \times 10^{2} \mathrm{~s}^{-1}$.

The value of $\mathrm{V}_{1}$ has been chosen such that the maximum value of sprite velocity is about $4 \%$ of the velocity of light. Similarly, the value of $\mathrm{I}_{1}$ corresponds to a peak current of 5 $\mathrm{kA}$. These values are in accordance with the experimental observations $[16,17,18]$. The time variation of velocity and current of red sprites have been shown in Fig. 9 and Fig. 10 respectively.

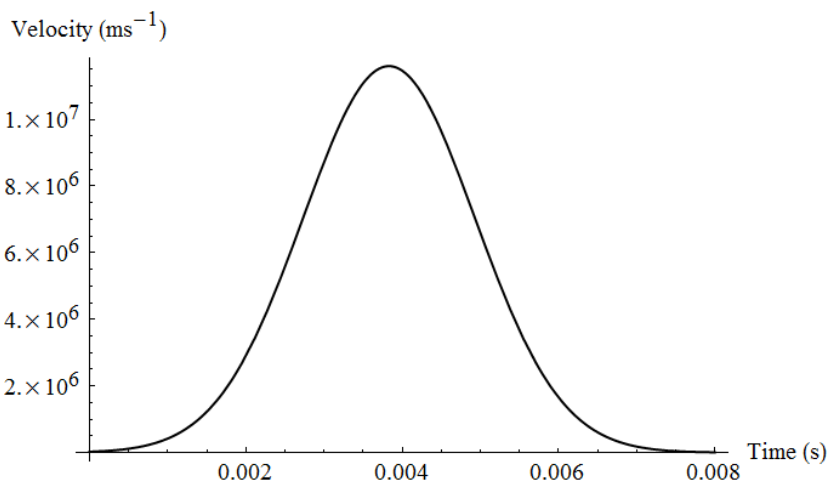

Figure 9: Velocity of red sprites with time.

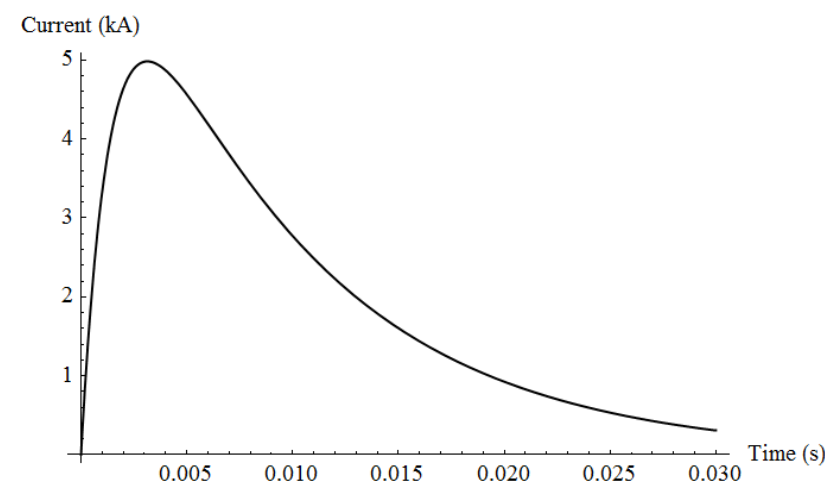

Figure 10: Sprite current with time.

$\mathrm{M}_{\mathrm{c}}(\omega)$ for red sprites has been calculated using equations (13), (14) and (15), consequently electric and magnetic fields can be calculated using equations (3) and (4) respectively. The current moment of red sprites in time domain has been shown in Fig. 11. The peak value of $M_{c}$ for red sprites comes out to be around $260 \mathrm{kA} . \mathrm{km}$. Cummer at al. [17] measured the current moment of three sprites and reported peak values range from 150 to $240 \mathrm{kA} . \mathrm{km}$. So, the calculated peak value of $\mathrm{M}_{\mathrm{c}}$ is well in conformity with the experimental results.

The calculated electric and magnetic fields associated with red sprites in Earth-ionosphere waveguide have been shown in Fig. (12-13) and Fig. (14-15) respectively. The electric and magnetic fields get peak at the SR frequencies. The calculated electric and magnetic fields have been found to be of the order of $10^{-3} \mathrm{Vm}^{-1}$ and $10^{-6} \mathrm{Am}^{-1}$ respectively. Magnitudes of sprites electromagnetic fields are much larger than RS-LC system. 


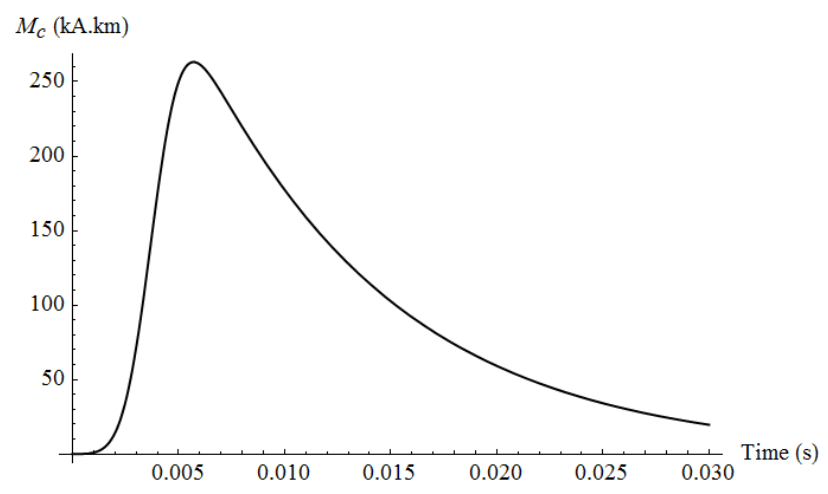

Figure 11: Current moment of red sprite with time.

One may notice that the average electric field of red sprites (Fig. 12) at a distance of $1000 \mathrm{~km}$ remains almost constant with frequency while that due to RS-LC system increase with frequency. The source electric field due to RS-LC system peaks at around $5 \mathrm{kHz}$ [5] and that due to sprites has maximum in the ELF range having a broad maximum in the frequency range $0-100 \mathrm{~Hz}[5]$ and then decreases sharply. These variations at the source spectrum make the field in Fig. 5 to rise with frequency while that in Fig. 12 to remain almost constant.

Further, one can notice that the electric field at a distance of $5000 \mathrm{~km}$ (Fig. 13) does not have clear peak in second harmonic while for magnetic field (Fig. 15) the second harmonic has sharp peak. Nickolaenko et al. [7] also obtained in their calculation that the electric field for a transient event has a clear peak of second harmonic in magnetic field component at $5000 \mathrm{~km}$ while the electric field component at the same distance the second harmonic is diffused.

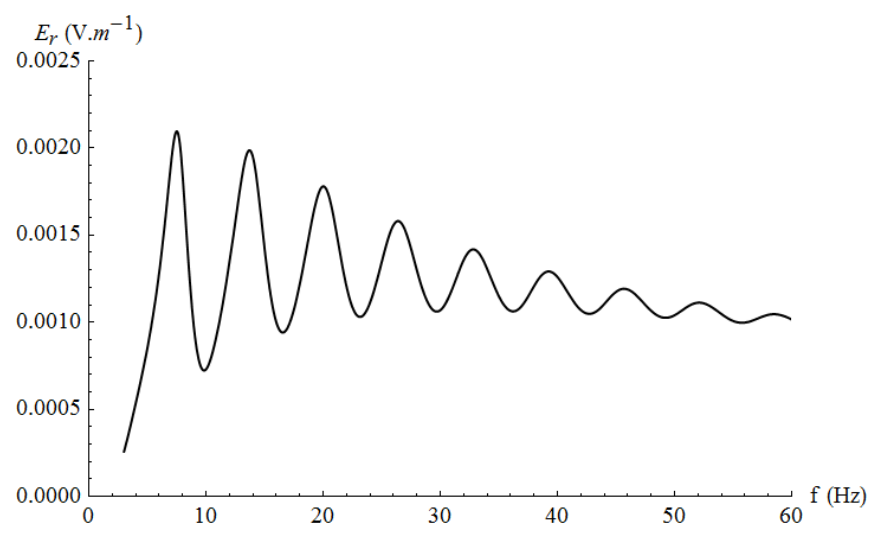

Figure 12: Electric field versus frequency at a distance of $1000 \mathrm{~km}$ from the source.

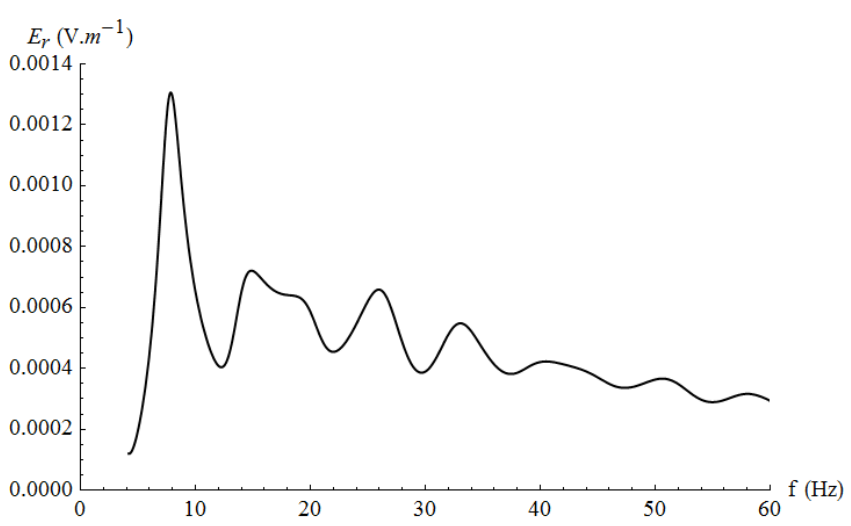

Figure 13: Electric field versus frequency at a distance of $5000 \mathrm{~km}$ from the source.

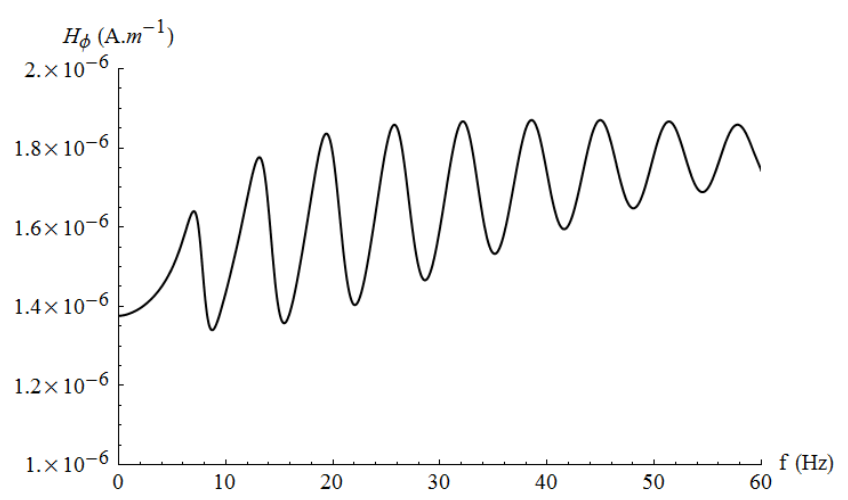

Figure 14: Magnetic field versus frequency at a distance of 1000 $\mathrm{km}$ from the source.

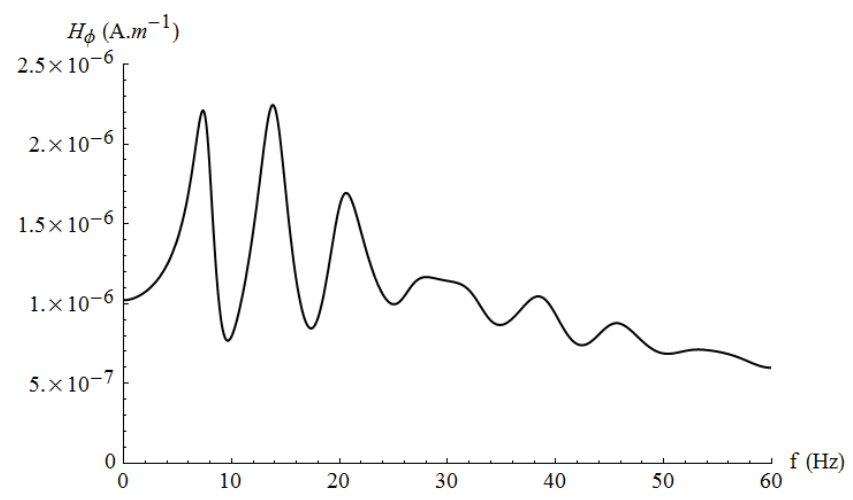

Figure 15: Magnetic field versus frequency at a distance of $5000 \mathrm{~km}$ from the source.

\section{Results Discussion and Conclusion}

Electric and magnetic fields from RS-LC system and red sprites in Earth-ionosphere waveguide have been calculated. Calculations have been made at distances of $1000 \mathrm{~km}$ and $5000 \mathrm{~km}$ from the source. The ionospheric reflection from red sprites as per our estimates becomes effective beyond a distance of about $700 \mathrm{~km}$. Nickolaenko et al. [7] have made calculations at 2, 5, 10 and 15 thousand kilometers. Ando et al. [19] also synthesized the observed Schumann resonance 
at distance ranging from 5000 to $13000 \mathrm{~km}$. In our representative calculations, we have taken the distances of $1000 \mathrm{~km}$ and $5000 \mathrm{~km}$. Both the electric and magnetic fields contribute to SR and get peak at around 7.7, 14.0, 20.0, 26.0, $32.2 \mathrm{~Hz}$ and so on. Madden and Thompson [4] obtained the SR frequencies to be $7.8,14.1,20.3,26.3$ and $32.5 \mathrm{~Hz}$. The daily variation in SR frequencies can be around $+0.5 /-0.5$ Hz. Recently, Chand et al. [3] reported the experimental results of electric and magnetic fields associated with the first three SR frequencies $7.8,14.0$ and $20.0 \mathrm{~Hz}$. They observed diurnal variation in the SR frequencies associated with magnetic field components, the maximum frequency variation of about $0.3,0.4$ and $0.7 \mathrm{~Hz}$ was observed in the first, second and third mode respectively. The variation in first and second mode SR frequency occurred during the intense solar X-ray bursts by $\sim 0.2 \mathrm{~Hz}$ and $0.3 \mathrm{~Hz}$ respectively [20]. Our theoretical calculations of SR frequencies are in good agreement with the experimental observations $[3,4]$.

Polk [21] reported the vertical electric field range as $0.22 \times 10^{-3}-1.2 \times 10^{-3} \mathrm{Vm}^{-1}$ by considering the first three resonance peaks. König [22] reported the typical electric and magnetic fields strength as $1 \times 10^{-3} \mathrm{Vm}^{-1}$ and $10^{-5} \mathrm{Am}^{-1}$ respectively. Williams [23] reports 5 years of SR magnetic field intensity measurements from Rhode Island with monthly mean $8 \mathrm{~Hz}$ mode intensities in the range $1.03 \times 10^{-6}$ to $5 \times 10^{-6} \mathrm{Am}^{-1}$. The calculated SR electric and magnetic fields strength from RS-LC system has been found of the order of $10^{-5} \mathrm{Vm}^{-1}$ and $10^{-8} \mathrm{Am}^{-1}$ respectively at 1000 and $5000 \mathrm{~km}$ from the source. Similarly, the calculated electric and magnetic fields strength from the red sprites has been found to be of the order of $10^{-3} \mathrm{Vm}^{-1}$ and $10^{-6} \mathrm{Am}^{-1}$ respectively at both 1000 and $5000 \mathrm{~km}$ from the source. If we compare our results with the experimental observations reported above [21,22,23], the electromagnetic fields strength associated with red sprites are of the same order, however the strength of electromagnetic fields associated with RS-LC system is very low.

One finds that the current of the RS-LC system is many times larger than the red sprite current. However, because of the large channel length of sprites, its current moment becomes much larger than the current moment of RS-LC system. A large current moment gives rise to large electric field. The spectrum also depends upon the rate of change of current moment which is larger for red sprites. As mentioned above the field strengths calculated for the first few resonant peaks of Schumann resonances are comparable to various experimental observations [21, 22, 23]. The calculations for RS-LC system for the same distance are about two orders of magnitude smaller than that due to red sprites. Thus the red sprites are more likely to generate Schumann resonances.

SR can be used to study the global lightning activity by tracking changes in the SR field intensities. Williams [23] suggested that SR may provide the useful information to monitor the global temperature. The SR frequency variation can be used to determine the daily variation of electron density $\mathrm{N}_{2}$.
Electromagnetic fields from RS-LC system and red sprites get very sharp peaks at smaller distances like $1000 \mathrm{~km}$, but peaks become fader as the distance of observation increases. The electric field component of fundamental SR frequency at $1000 \mathrm{Km}$ is 1.59 times to that at $5000 \mathrm{Km}$. This ratio is increased to 2.85 for the first harmonic. Similarly, the ratio of field strength of fundamental SR frequency at a distance of $1000 \mathrm{Km}$ to that at $5000 \mathrm{Km}$ for red sprites is 1.69 while for the first harmonic it is 3.3. In the calculations of Nickolaenko et al. [7], the peaks at resonance frequencies at $2000 \mathrm{~km}$ are sharp while those at 5000, 10000 and 15000 $\mathrm{km}$ are faded. The results are similar in the magnetic field component. In our calculation, the magnetic field component (Fig. 14) due to red sprites at a distance of $1000 \mathrm{~km}$ on average increases with frequency. The same trend has been obtained in the electric field due to RS-LC system at a distance of $1000 \mathrm{~km}$. Nickolaenko et al. [7] also for ELF transient events (Q-bursts) found that the average electric field was increasing with frequency in the magnetic field component at a distance of $5000 \mathrm{~km}$. Positive CG lightning associated with red sprites excite the Earth-ionosphere waveguide [24]. Cummer et al. [17] have observed that the total current moment associated with sprite-producing lightning has two distinct peaks. They described that the second peak having slow tail corresponds the current flowing in the sprite body itself. Slow tails of spriteassociated lightning flashes have been observed in the ELF range [25, 26], in the lower ELF range, [15] and in the ULF/ELF transition range [27].

A question arises whether SR are related to sprites. Earlier it was thought that the return stroke is the only source to excite earth-ionospheric waveguide producing Schumann resonances. However, we have found that the field strengths calculated for red sprites is in excellent agreement with the experimental observations of field strength of Schumann resonances observed by various workers [21, 22, 23]. The field strength due to RS-LC system is about two orders of magnitude lower than that due to red sprites. Therefore it is concluded that the red sprites may contribute to SR occurring in the earth-ionosphere waveguide significantly.

\section{Acknowledgements}

Author Manoj Kumar Paras is thankful to CSIR New Delhi, India for their financial support to carry out this research work. Also, we are thankful to the reviewers for their valuable comments and suggestions.

\section{References}

[1] S. A. Cummer, "Modeling electromagnetic propagation in the Earth-ionosphere waveguide," IEEE Trans. Antennas and Propagation, vol. 48, no. 9, pp. 2-12, 2000 .

[2] W. O. Schumann, "U" ber diestrahlungslosen Eigenschwingungen einer leitenden Kugel, die von einer Luftschicht und einer Ionosph"arenh"ulleumgebenist," Z. Naturforsch., vol. 7a, pp. 149-154, 1952. 
[3] R. Chand, M. Israil, and J. Rai, "Schumann resonance frequency variations observed in magnetotelluric data recorded from Garhwal Himalayan region India," Ann. Geophys., vol. 27, no. 9, pp. 3497-3507, 2009.

[4] T. Madden and W. Thompson, "Low frequency electromagnetic oscillations of the Earth-ionosphere cavity," Rev. Geophys., vol. 3, no. 2, pp. 211-254, 1965.

[5] M. K. Paras and J. Rai, "Electric and magnetic fields from return stroke-lateral corona system and red sprites," J. EM Ana. App., vol. 3, no. 12, pp. 479-489, 2011.

[6] M. K. Paras and J. Rai, "Electrical parameters of red sprites," Atmosfera, vol. 25, no.4, pp. 371-380, 2012.

[7] A. P. Nickolaenko, M. Hayakawa, and Y. Hobara, "Qbursts: Natural ELF radio transients," Surv. Geophys., vol. 31, no. 4, pp. 409-425, 2010.

[8] D. Singh, R. P. Singh, A. K. Kamra, P.N. Gupta, R. Singh, V. Gopalakrishnan, and A. K. Singh, "Review of electromagnetic coupling between the Earth's atmosphere and the space environment," J. Atmos. Sol.Terr. Phys., vol. 67, no. 6, pp. 637-658, 2005.

[9] L. B. Loeb, "Confirmation and extension of a proposed mechanism of the stepped leader lightning stroke," $J$. Geophys. Res., vol. 73, no.18, pp. 5813-5817, 1968.

[10]J. Rai, "Current and velocity of the return stroke lightning," J. Atmos. Terr. Phys., vol. 40, no. 12, pp. 1275-1280, 1978.

[11]P. P. Pathak, "Some studies on lightning," Ph.D. Dissertation, University of Roorkee, Roorkee, India, 1982.

[12] V. P. Pasko, U. S. Inan, T. F. Bell, and, Y. N. Taranenko, "Sprites produced by quasi-electrostatic heating and ionization in the lower ionosphere, $J$. Geophys. Res., vol. 102, no. A3, pp. 4529-4561, 1997.

[13]R. C. Franz, R. J. Nemzek, and J. R.Winckler, "Television image of a large upward electrical discharge above a thunderstorm system," Science, vol. 249, no. 4964, pp. 48-51, 1990.

[14]D. D. Sentman and E. M. Wescott, "Red sprites and blue jet: Thunderstorm-excited optical emissions in the stratosphere, mesosphere and ionosphere," Phys. Plasmas, vol. 2, no. 6, pp. 2514-2522, 1995.

[15] D. J. Boccippio, E. R. Williams, S. J. Heckman, W. A. Lyons, I. T. Baker, and R. Boldi, "Sprites, ELF transients, and positive ground strokes," Science, vol. 269, no. 5227, pp. 1088-1091, 1995.

[16]J. Li and S. A. Cummer, "Measurement of sprite streamer acceleration and deceleration," Geophys. Res. Lett., vol. 36, no. L10812, pp. 1-5, 2009.

[17] S. A. Cummer, U. S. Inan, T. F. Bell, and C. P. Barrington-Leigh, "ELF radiation produced by electrical currents in sprites," Geophys. Res. Lett., vol. 25, no. 8, pp. 1281-1284, 1998.
[18] M. J. Rycroft and A. Odzimek, "Effects of lightning and sprites on the ionospheric potential and threshold effects on sprite initiation, obtained using analog model of the global atmospheric electric circuit," J. Geophys. Res., vol. 115, A00E37, pp. 1-18, 2010.

[19] Y. Ando, M. Hayakawa, A. V. Shvets, and A. P. Nickolaenko, "Finite difference analyses of Schumann resonance and reconstruction of lightning distribution," Radio Sci., vol. 40, no. RS2002, pp. 1-14, 2005.

[20] V. C. Roldugin, Y. P. Maltsev, A. N. Vasiljev, A. Y. Schokotov, and G. G. Belyajev, "Schumann resonance frequency increase during solar X-ray bursts," $J$. Geophys. Res., vol. 109, no. A01216, pp. 1-8, 2004.

[21] C. Polk, "Schumann Resonances, in CRC Handbook of Atmospherics, vol. 1, pp. 111-177, 1982.

[22] H.L. König, "ELF and VLF signal properties: Physical characteristics, In ELF and VLF Electromagnetic Field Effects, M.A. Persinger (Editor), Publ. Plenum Press, New York, 1974.

[23]E.R. Williams, "The Schumann resonance: A global tropical thermometer," Science, vol. 256, no. 5060, pp. 1184-1187, 1992.

[24] M. Füllekrug and S. C. Reising, "Excitation of Earthionosphere cavity resonances by sprite associated lightning flashes," Geophys. Res. Lett., vol. 25, no. 22, pp. 4145-4148, 1998.

[25] S. C. Reising, U. S. Inan, T. F. Bell, and W. A. Lyons, "Evidence for continuing currents in sprite-producing lightning flashes," Geophys. Res. Lett., vol. 23, no. 24, pp. 3639-3642, 1996.

[26] S. A. Cummer and U. S. Inan, "Measurement of charge transfer in sprite-producing lightning using ELF radio atmospherics," Geophys. Res. Lett., vol. 24, no. 14, pp. 1731-1734, 1997.

[27] M. Füllekrug, S. C. Reising, and W. A. Lyons, "On the accuracy of arrival azimuth determination of spriteassociated lightning flashes by Earth-ionosphere cavity resonances," Geophys. Res. Lett., vol. 23, no. 25, pp. 3691-3694, 1996. 